\title{
Equality of opportunity for work experience? Computing students at two UK universities "play the game"
}

Sally Smith ${ }^{1}$, Ella Taylor-Smith ${ }^{1}$, Liz Bacon $^{2}$ and Lachlan Mackinnon ${ }^{2}$

\begin{abstract}
A recent UK Government commissioned study found concerning levels of unemployment among computing students from disadvantaged, black and minority ethnic backgrounds. The study highlighted that work experience was a factor in increased levels of graduate employment. As such, it is vital that students have equal access to such work experience. This study considers the availability of work experience to 140 computing students at two city centre UK universities. Data analysis considered socioeconomic background and ethnicity to determine if these influenced attitudes to work experience. While students' socioeconomic backgrounds and ethnicity had little influence on their interest in work experience, patterns of success in gaining work experience reflected worrying graduate (un)employment patterns, with those from disadvantaged, black or minority ethnic backgrounds less able to secure work experience. These findings have serious implications for university and government policies promoting work experience and highlight the need for national interventions.
\end{abstract}

\section{Keywords}

Work experience; computing; ethnicity; socioeconomic background; student placement.

\footnotetext{
${ }^{1}$ Edinburgh Napier University

${ }^{2}$ University of Greenwich
} 


\section{Introduction}

Globally, higher education (HE) is becoming a High Participation System, as increasing proportions of each country's population go to university (Marginson 2016). However, there has not been a proportional increase in vacancies that traditionally require HE degrees; rather, graduates fill jobs that were previously non-graduate roles and employers look for more than a degree from prospective employees (Darr \& Warhurst 2008; Farenga \& Quinlan 2015). In 2009, the unemployment rate among computer science graduates was $18.1 \%$ compared with an all-subject rate of 10.0\% (HESAb 2016). Although unemployment rates have declined, computing has remained the worst performing discipline. The UK Government commissioned a UK-wide review of computing graduate employment to identify discipline challenges (Shadbolt 2016), including computing graduates' comparatively slower move into graduate jobs (BIS 2016, 62). The review revealed a complex picture of university stratification, concerns about Black and Minority Ethnic (BME) graduates, and wide variations in employer expectations of both technical and soft skills (Shadbolt 2016). One of the recommendations of the report was to increase the availability of opportunities for relevant student work experience. In recent years, the numbers on traditional computing sandwich degrees (with one year placement) have declined. While reasons for this decline have not been fully explored, student funding models have played a part (Docherty, Jones \& Sileryte 2015), together with a (probably related) reduced student demand for placement years (Ramirez et al. 2016). To meet Shadbolt's recommendation, new models for gaining work experience are required, taking into account both students' and employers' preferences, to ensure uptake and useful outcomes. However, we know little about students' attitudes to work experience, their approaches to gaining work experience, and the results of their efforts. This study was designed to ask undergraduate computing students about their attitudes and experiences and, by taking their contexts into account, reveal some of the challenges faced by individuals in approaching work experience.

\section{Work experience, employability, and social mobility}

There is a widely acknowledged demand for skilled computer science graduates (for example, Blackwood 2016, UKCES, 2015). So the relatively high graduate unemployment rates for computing (HESAb 2016) are something of a conundrum (Smith 2016). Efforts to explain the phenomenon include a recognition of the wide range of roles available to computing graduates, combined with the many and diverse skills expected by their employers (Fincher \& Finlay 2016), as well as the off-shoring of technology industry jobs, especially in the UK context (Donnelly, Grimshaw, \& Miozzo, 2011). Furthermore, it has been suggested that computing students may be more interested in gaining technical skills than acquiring diverse professional skills: for example, university staff in Fincher and Finlay's study (2016) observed that their students were instrumentally motivated by their love of computers and coding, rather than their career prospects.

Within the overlapping contexts of demand for computing graduates and relatively high rates of unemployment, work experience is consistently associated with improved employment prospects for computing students and graduates (BIS 2016; Docherty et al. 2015; Farenga \& Quinlan 2015; Fincher \& Finlay 2016; Shadbolt 2016). Silva, Lopes, Costa et al (2016) demonstrated that sandwich courses with internships significantly decreased graduate unemployment, compared to first-cycle degrees without integrated internships. There are many similarities in their study of Portugal with the UK context, including a recognition of contextual influences such as the stratification of Higher Education Institutions and corresponding impact on employability (Jackson 2014; 
Marginson 2016; Spiegler \& Bednarek 2013). In the UK, opportunities for work experience and their take-up by students are limited (Docherty et al. 2015). Students need to actively compete for placements and internships, while studying for their degrees and potentially working to support themselves financially, leaving some with significant challenges (Bathmaker, Ingram, \& Waller 2013; Farenga \& Quinlan 2015; Ramirez et al. 2016).

University provides potential resources for social mobility, especially for computing students (Darr \& Warhurst 2008). However, all stages of this process are influenced by the students' backgrounds, including participation in university and work-based learning, level of award, and outcomes for graduates, such as future positions and pay (Bathmaker et al. 2013; Marginson 2016; Social Mobility Advisory Group 2016). Smith, Smith and Caddell (2015b) found that, while students valued the experience of work placements more than the pay per se, many of the students in their study would not have been able to take on unpaid placements. Indeed, unpaid internships were identified as a threat to equality of opportunity and universities should be mindful of this when considering fair access.

As a subject discipline in higher education, computer science is taught in the majority of universities, both established and modern, and is generally successful at attracting students from under-represented groups. Computing courses include students from Low Participation Neighbourhoods (LPN) at 14\% (compared with $10 \%$ for all STEM subjects) and Black and Minority Ethnic (BME) at 37\% (compared with 32\% for all STEM subjects) (Shadbolt, 2016). This discipline attractiveness to diverse groups is a reason to celebrate; but also a reason to consider whether, once recruited to a university course, there is equality of opportunity, leading towards a graduate job.

\section{Habitus, capitals, and playing the game}

Following Bathmaker et al. (2013), Burke (2015), and Farenga and Quinlan (2015), this study was underpinned by Bourdieu's concepts of habitus, capitals, and playing the game (1977). These provided frameworks to explore and describe the influence of students' backgrounds on their propensity to gain work experience, while they are at university, including their confidence (and support) in negotiating work experience processes and markets. With the concept of habitus, Bourdieu aims to describe an individual or group's social context, while encompassing both structure and (potential) agency (1977). Burke understands habitus as the "norms, values and dispositions directing agency or practice" $(2015,67)$. Habitus has been interpreted as a structure that determines our actions and Bourdieu has been criticised for emphasising the influence of structure over agency (Bathmaker 2015). However, Bourdieu's parallel concept of the game demonstrates that, while habitus influences people's options and dispositions, it is built on their actions, over time. Bourdieu adopted this game metaphor to reflect a social kind of competition, where an understanding of the rules and useful strategies for success are gradually acquired from close networks, such as family (Bourdieu, 1990). His concern is to provide a balance to ideologies that imply a level playing field in which individuals (and organisations) are equally responsible for their success or failure:

"Those who talk of equality of opportunity forget that social games - the economic game, but also the cultural games (the religious field, the juridical field, the philosophical field, etc.) are not 'fair games'. Without being, strictly speaking, rigged, the competition resembles a handicap race that has lasted for 
generations or games in which each player has the positive or negative score of all those who have preceded him, that is, the cumulated scores of all his ancestors" (Bourdieu 2000, 214-215).

The concept of habitus is increasingly used to discuss the influence of social class on people's paths through education and work; and the concept of playing the game is applied to the many activities students are expected to undertake, beyond their studies, to gain success in the graduate job market (e.g. Bathmaker et al. 2013; Bathmaker 2015; Brosnan 2017; Brown, Hesketh, \& Williams 2004; Burke 2015; Farenga \& Quinlan 2015; O'Shea 2016). In this study, student recognition of the value of work experience to them is taken to be an indication of understanding the rules of the game of graduate employment, where recognition includes attending preparatory workshops, submitting applications and attending interviews.

Capitals are resources for social mobility (O’Shea 2015) and "mobility within fields of power is contingent upon one's ability to deploy forms of economic, social and cultural capital” (Borlagdon 2015). Bourdieu describes four types of capital: economic capital; cultural capital (including education and cultural preferences); social capital (people and networks); and symbolic capital (prestige and legitimacy) (1985; Navarro 2006). Bourdieu developed the concept of capital, from Marxian ideas in which economic capital shapes society, to the more pluralistic, nuanced, and reflexive framework of capitals (Yamak, Ergur, Özbilgin, \& Alakavuklar 2016). Bourdieu's concept of symbolic capital draws attention to the resources that support recognition of prestige, legitimacy, meaning, value and power (Navarro 2006; Yamak et al. 2016). Tomlinson (2017) argues that this framework supports investigations of the myriad resources (or deficits) that may support our paths through study to working life. With symbolic capital, there are clear winners and losers (Yamak et al. 2016). For example, the Social Mobility Commission (2016), studying career progression in investment banking, identify the importance of a "particular portfolio of economic, social and cultural capital, which is more available to young people from privileged backgrounds" (p iii), including "speech patterns, accent, behaviour and dress" (p84). This may be presented as "polish" (p 84) or "face fitting” (Smith \& Smith 2016, 4). Employers, especially in times of insecurity, may be inclined to hire people that resemble their employees in order to maintain the status quo (Social Mobility Commission 2016, 108), in spite of equality legislation and evidence that diversity increases performance (Hunt, Layton, \& Prince 2015). Unfortunately, a characteristic such as race or gender may be perceived as making an individual more or less suited to a role by a potential employer (or even university staff). Using data from 2013-14, HEFCE (2015) found that white graduates were more likely than graduates from almost all BME groups to go into employment after graduation. For example, they found an unexplained difference of over seven percentage points below the reference group for Chinese and black African graduates; and these gaps increase over time (HEFCE 2015, 29; Social Mobility Advisory Group 2016, 5) ${ }^{1}$. Thus suggestions that increased access to capitals in themselves would increase social mobility over-state agentic endeavour; the term "glass floor" (Waller 2011, 9) captures this seemingly impermeable barrier to change.

In the context of computing students, our overarching question is whether they recognise the game and have sufficient capitals to be effective players? Through graduate employment rates, it can be seen that work experience, including internships and placements, is central to this game. In this study, we try to get a modest idea of students' habitus and the capitals available to them, combined with their awareness of the employability game - the activities students are increasingly expected to do, beyond their studies, to gain "prized graduate positions" (Chillas, Marks, \& Galloway 2015). The research questions to emerge, therefore, are: i) What are 
student attitudes to gaining relevant work experience? ii) Do attitudes and experiences vary according to socioeconomic status and/or ethnicity? The aim of this pilot study was to explore how computing students experience access to work experience in two universities with computing departments of similar size. Both universities attract students from diverse backgrounds. Both universities have positive approaches to paid computing placements, including infrastructure in the form of placement staff and placement courses.

\section{Methodology}

\section{Gathering data from students}

Undergraduate computing students were surveyed at two post-1992 universities ${ }^{2}$, one in Scotland (University S.) and one in England (University E.). Both universities have urban campuses and large computing departments. The survey instrument drew upon several studies, primarily conducted within University $S$, into student/graduate perceptions of employability initiatives (e.g. Smith, Berg, \& Smith 2015a; Smith et al. 2015b; Smith, Smith, Taylor-Smith, \& Fotheringham 2017). Following Bourdieu (e.g. 2000), the survey questions were also designed to gather information about the students' backgrounds and their understanding of the employability 'game' (Bathmaker et al. 2013).

Students were invited to participate by email, through in-class presentations, and at events. Students in later years were targeted, so that they would have relevant experience. A face-to-face survey (personal interview survey) method was chosen in order to gather responses to all relevant questions, avoiding respondents giving up, skipping questions, or misunderstanding crucial terms. In previous surveys, conducted by the research team, respondents had misinterpreted terms such as "work experience", "work-based learning", "placement", and “internship". This was evident through mismatches between a respondent's answers within the survey and seemed to lead to respondents omitting information about their own relevant experience. In this study, interviewers encouraged students to understand these terms widely and inclusively and to provide any relevant data. Interviewers also encouraged respondents to complete each survey as far as possible, including unpopular questions, such as asking students to describe their social class. The disadvantages of this method include potential interviewer bias, potential reluctance for respondents to answer sensitive questions, and time pressures. There is also a relatively high cost per respondent and geographical limitations, compared to paper or online surveys (Szolnoki \& Hoffmann 2013, 58). In practice, the face-to-face survey methodology could only be implemented in certain situations and more flexible methods were adopted to fit the contexts in which the researchers encountered the students. These included students completing the survey under the guidance of researchers or completing the survey individually. Where possible the researchers checked through the completed survey with the respondent to identify any gaps or mismatches. Surveys were completed on paper. Various small incentives were provided to recognise the time the students contributed to the project.

\section{Ethical procedures}

The research fully complied with each university's ethical requirements. Specifically, each respondent was provided with written information about the study, including how their data would be handled. Respondents signed informed consent forms and these were immediately separated from the anonymised data. The questionnaire was reviewed by the Equality and Diversity Office at University E. 


\section{Results}

\section{Demographics}

The gender balance in both sets of respondents was similar, with $18.6 \%$ of respondents of each university identifying as female. The percentage of women studying computing in the UK is $16.5 \%$ (HESAa). Comparison figures for full-time undergraduate computing students in 2016/17 are University E: 19\%; University S: $15 \%$. Most respondents were under 25, though University S respondents were a little older (42.9\% over 25, compared to $11.4 \%$ of University E respondents). Reflecting the four year degree in Scotland, most University $\mathrm{S}$ respondents were in their $3^{\text {rd }}$ or $4^{\text {th }}$ year of study ( 31 and 32 respectively), whereas most University $\mathrm{E}$ respondents were in their $2^{\text {nd }}$ year $\left(49 ; 13\right.$ in $3^{\text {rd }}$ year and 8 in $4^{\text {th }}$ year). As shown in Figure 1 , respondents' ethnicity reflected the relative diversity of the two universities: $92.8 \%$ of University $\mathrm{S}$ respondents were white, including $27.1 \%$ from Europe, beyond the UK; whereas over half the University E respondents identified nonwhite ethnic backgrounds, including $11.4 \%$ black African, 8.6\% Asian Indian, and 7.1\% Asian Chinese. The ethnic background options are based on previous Scottish Funding Council (SFC) categories.

\section{Figure 1: Ethnic background}

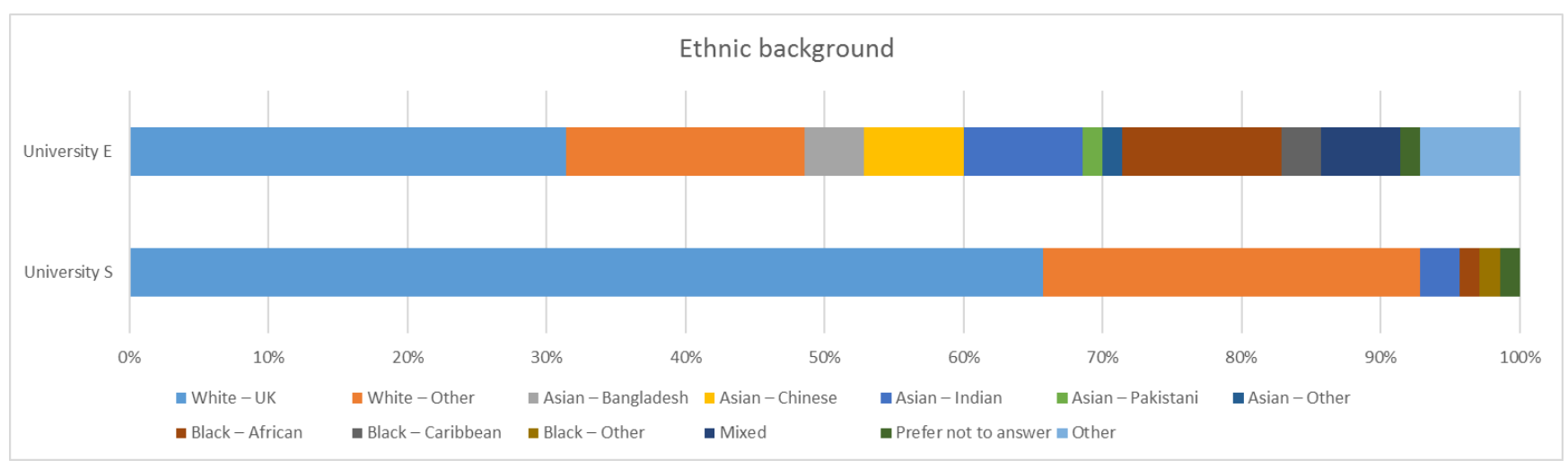

Students were asked their social class as free text, providing the examples working class and middle class, specifically: "How would you describe your class? (e.g. working class, middle class, etc.)". Table 1 summarises the responses. Just over half the students identified as working class, including more University E than University S students (65.7\% compared to 50\%). The students' self-identification was triangulated with their parents' higher education. For 58.6\% of respondents, neither parent had attended university or polytechnic (according to their offspring); for $23.6 \%$, one parent had attended; for 17.9\%, both parents had attended. Reflecting the social class figures, fewer students from University E came from families where the parents had higher education than University S. Neither parent had attended HE for $65.7 \%$ of University E respondents and $51.4 \%$ of University S respondents. The relationship between social class and parents' HE was found to be significant, with a Pearson Chi Squared score of 0.01 .

Table 1: Respondents' social class

\begin{tabular}{|l|l|l|l|l|l|}
\hline & Working class & $\begin{array}{l}\text { Working to } \\
\text { middle class }\end{array}$ & Middle class & $\begin{array}{l}\text { Middle to } \\
\text { upper class }\end{array}$ & $\begin{array}{l}\text { Blank or no } \\
\text { comment }\end{array}$ \\
\hline University S $(\mathrm{n}=70)$ & $35(50.0 \%)$ & $5(7.1 \%)$ & $26(37.1 \%)$ & $1(1.4 \%)$ & $3(4.3 \%)$ \\
\hline University E $(\mathrm{n}=70)$ & $46(65.7 \%)$ & $1(1.4 \%)$ & $16(22.9 \%)$ & $0(0 \%)$ & $7(10 \%)$ \\
\hline Total & $81(57.9 \%)$ & $6(4.3 \%)$ & $42(30 \%)$ & $1(0.7 \%)$ & $10(7.1 \%)$ \\
\hline
\end{tabular}




\section{Students' agency and awareness of the game}

Students were asked whether their degree course included a placement (optional or compulsory) and whether this affected their choice of university and degree. They were asked further about their motivations for choosing their degree and whether they recognised the importance of work experience at the beginning of the course and as their studies progressed. The responses to these questions help to build a picture of the students' awareness of their choices and activities at university as part of their career planning. Combining responses from both universities, $80.8 \%$ of respondents recognised that their course offered a compulsory or optional placement and only $5.7 \%$ did not know. However, this only influenced a quarter (26\%) of respondents in their choice of degree programme and university. From multiple-choice answers, the students' strongest motivations for this choice were "of interest" (69.7\%), "for a specific career path" (59.7\%), "subjects were enjoyable" (33.8\%), and "placement or work-related opportunities (20.8\%). Options which indicated less agency in decision-making were distinctly less popular: only $4.3 \%$ admitted "parental influence" and only one person was motivated by "subjects were easy". The respondents were asked to rate their agreement with two statements about work experience: "When I started my course I knew that I wanted to gain relevant work experience" and "As my studies progressed, I came to realise that gaining relevant work experience would be useful". $73.6 \%$ agreed or strongly agreed with the first statement; $90.6 \%$ agreed or strongly agreed with the second statement. This increase in interest was further reflected by a move from agree to strongly agree: where $34.3 \%$ of students strongly agreed with the first statement, 59.9\% strongly agreed with the second statement. This set of responses indicates that the students generally had a good awareness of how their choices and activities at university could or would impact on their future careers. This is in marked contrast to pictures of students with tunnel-vision focus on their studies (or their social life). These students were aware of the basics of the employability game.

To get an idea of where this awareness came from, respondents were asked about who they would go to for advice and who they received encouragement from. Students were asked to agree or disagree that they were encouraged to gain work experience by various university staff, family, friends, and other students. $76.1 \%$ agreed (including strongly agreed) that their lecturers encouraged them and 75\% agreed they were encouraged by placement /careers staff; whereas $59.2 \%$ were encouraged by their family and the same for friends; $55.2 \%$ were encouraged by other students. Over half the students had looked for help or advice on making job/ placement applications (57.9\%) and 61.6\% of these had sought advice from placement and careers staff at their university; with $31.3 \%$ seeking advice from teaching staff and $33.3 \%$ consulting online resources; $33.3 \%$ had asked their parents and $23.2 \%$ had asked other family members. Respondents were also asked in free text about whose advice had been most valuable. The most popular frequent responses included references to placement and careers staff (27), teaching staff (22), parents and family (22), with 12 people citing industry connections, such as industry mentors and colleagues they had met during work experience. In this picture, both universities and families are supporting students to gain work experience, but the resources provided by the universities are proving more useful in this context.

The relevant resources provided by the universities were assessed by asking the students whether they had attended any events that might help them prepare for work experience. $37.4 \%$ had attended more than one event or undertaken an employability skills or professionalism module; and a further $23.7 \%$ had attended one event (or just answered "yes"). Respondents were asked which events they found useful. The most popular events (from 
free text responses) were CV-writing (30 mentions) and mock-interviews (20). Other popular responses were employer networking events (10), mentoring scheme events (9), and placement fairs etc. (6). This short catalogue gives a reasonable overview of the employability activities currently provided by the two universities.

\section{Influence of social class and ethnicity on applying for and gaining work experience}

The data gathered that relates to habitus is the students' social class (via self-identification and parents' higher education) and their ethnicity. As the sample is relatively small, the sub categories of social class and ethnicity do not contain enough data to provide significant results. However, there did seem to be some differences in students' overall experience of the application process associated with gaining work experience according to their social class and ethnicity, which might become clearer in either a wider or deeper study. Students were asked various questions about their experiences, including the free text instruction "Please could you describe any work experience (e.g. placement or internship) since you started your course”. Students were asked about: the perceived benefits or drawbacks of work experience; whether they had applied; and the application process and results (if applicable).

Table 2: Have you ever applied to get work experience relevant to your degree? Were you offered work experience?

\begin{tabular}{|r|c|c|c|c|c|c|c|}
\hline & \multicolumn{2}{|c|}{ Applied for work experience } & \multicolumn{4}{|c|}{ Offered work experience } \\
\hline & $\begin{array}{r}\text { n (applied/ } \\
\text { not applied) }\end{array}$ & Yes applied & $\begin{array}{c}\text { No did not } \\
\text { apply }\end{array}$ & $\begin{array}{c}\text { n (offered/ } \\
\text { not offered) }\end{array}$ & $\begin{array}{c}\text { Offered } \\
\text { work exp. }\end{array}$ & $\begin{array}{c}\text { Not offered } \\
\text { work exp. }\end{array}$ & $\begin{array}{c}\text { Other/ } \\
\text { haven't } \\
\text { heard yet }\end{array}$ \\
\hline $\begin{array}{r}\text { Both parents attended } \\
\text { HE }\end{array}$ & 25 & $16(64 \%)$ & $9(36 \%)$ & 14 & $9(64.2 \%)$ & $4(28.6 \%)$ & $1(7.1 \%)$ \\
\hline $\begin{array}{r}\text { One parent attended } \\
\text { HE }\end{array}$ & 33 & $20(60.6 \%)$ & $13(39.4 \%)$ & 20 & $13(65 \%)$ & $4(30 \%)$ & $1(5 \%)$ \\
\hline Neither attended HE & 82 & $53(64.6 \%)$ & $29(35.4 \%)$ & 50 & $26(52 \%)$ & $20(40 \%)$ & $4(8 \%)$ \\
\hline Working class & 81 & $51(63 \%)$ & $30(37 \%)$ & 47 & $23(48.9 \%)$ & $19(40.4 \%)$ & $5(10.6 \%)$ \\
\hline Working to middle & 6 & $4(66.7 \%)$ & $2(33.3 \%)$ & 4 & $3(75 \%)$ & $1(25 \%)$ & $0(0 \%)$ \\
\hline class & 42 & $26(61.9 \%)$ & $16(38.1 \%)$ & 25 & $16(64 \%)$ & $9(36 \%)$ & $0(0 \%)$ \\
\hline Middle class & 1 & $1(100 \%)$ & $0(0 \%)$ & 1 & $1(100 \%)$ & $0(0 \%)$ & $0(0 \%)$ \\
\hline Blank /n.c. re class & 10 & $7(70 \%)$ & $3(30 \%)$ & 7 & $5(71.4 \%)$ & $1(14.3 \%)$ & $1(14.3 \%)$ \\
\hline White & 99 & $60(60.6 \%)$ & $39(39.4 \%)$ & 58 & $35(60.3 \%)$ & $19(32.8 \%)$ & $4(6.9 \%)$ \\
\hline BME & 39 & $28(71.8 \%)$ & $11(28.2 \%)$ & 25 & $13(52 \%)$ & $10(40 \%)$ & $2(8 \%)$ \\
\hline
\end{tabular}

Table 2 shows the same categories for answers to the questions "Have you ever applied to get work experience relevant to your degree?" and "Were you offered work experience, and have you started it/ completed it?" Both questions offered multiple-choice answers. The answers to the second question have been simplified, so that answers indicating that the student has been offered work experience have been collapsed into one category. This category includes: "Offered, but haven't started it"; "I've started it"; "I've completed it"; and "I've been offered it, but I can't do it”. In the responses to these questions, students whose parents attended HE were no more likely than students whose parents did not attend HE to have applied for work experience (64\% and 64.6\%). However, students whose parents attended HE were more likely than students whose parents did not attend HE to have been offered work experience (64.2\% compared to 52\%). Students who identified as middle class were very slightly less likely than students who identified as working class to have applied for work 
experience (61.9\% compared to 63\%); but much more likely to have been offered work experience (64\% compared to $48.9 \%$ ). BME students were more likely to have applied for work experience than white students (71.8\% compared to $60.6 \%$ ). However, BME students were rather less likely to have been offered work experience $(52 \%$ compared to $60.3 \%)$.

\section{Discussion}

This study sought to reveal attitudes to, and experiences of, gaining work experience for undergraduate computing students at two universities. Of particular interest was whether there were different attitudes between students aligned to the characteristics of self-reported social class; those whose parents had been at university; and ethnicity. To consider students' attitudes to work experience the discussion is presented in three sections: recognising the role of work experience; knowing how to access work experience; and gaining work experience.

\section{Recognising the role of placement}

Recent critical research into student placements in the ICT sector has found that internships "are a mechanism by which already advantaged students maintain their privileged position" (Chillas et al. 2015, 12). For the two universities in the study, work experience was generally viewed by staff as a way of evening out the advantages in the labour market that graduates from elite institutions enjoy (Clark \& Zuckas 2015). It is clear from the data that the benefits of work experience were understood by most students. Students at both universities realised work experience was important for career aspirations, for example to discover more about relevant ICT professions (Jackson 2014). Tomlinson considers students' interest in and understanding of the value and purpose of interactions with employers to be evidence of cultural capital (2017). There was evidence that academic and careers staff had contributed to explaining the benefits of gaining work experience - the "rules of the game" (Bathmaker et al. 2013) — to all students. Indeed, students recognised encouragement from a range of sources: lecturing staff, placement/ careers staff, and family were all sources of encouragement and this was consistent between the two universities; and with findings elsewhere (Greenbank 2011). However, levels of interest vary with context: for example, Doherty et al. (2015) and Ramirez et al. (2016) found that, in general, students preferred to complete their degrees early and start a graduate role rather than interrupt their studies to undertake work experience. In their study, Ramirez et al. (2016) also found that placements were seen as a distraction to study or on-campus socialising. The next consideration is, having some appreciation of the rules, whether (and how) students engage with the preparation and application processes.

\section{Applying for work experience}

Beyond recognising how work experience can support overall aims of a graduate career, some students knew more about how to apply for placement than others. Most students sought advice on making applications; however, this was more prevalent at University E (65.7\% compared with 50\%). Advice was sought in the main from placement / careers staff, especially at University E. As both universities have high profile placement offices this finding needed deeper exploration. It seemed that the industry-mentoring programme at University E was an additional factor in seeking advice on applications. In Carbone and Hamilton's Australian study (2016), students identified industry mentors as a way of improving their employment outcomes, for example, as being helpful in understanding the attributes companies are looking for in recruitment and employment. 
While recognising the benefits, not all students attended events designed to prepare them for work experience. Lack of engagement has been observed elsewhere (for example, Sin \& Neave 2016; Tymon 2013). Students have been found to avoid events where they believe there is a poor cultural fit (Clark \& Zukas 2013), i.e. the sense that "this isn't for me". The events that were well attended represented specific, personalised services such as CV workshops and mock interviews. These are well-understood techniques with accessible and achievable aims. Tomlinson argues that these are opportunities "to harness embodied dispositions and behavioural competences" $(2017,345)$. However, in this study, the popularity of these activities could reflect that they were the specific examples given in the survey.

Students have been found to give up following unsuccessful applications, where they lack confidence and resilience (Doherty et al. 2015). The time taken to complete numerous application forms and intense recruitment processes have also been identified as a barrier (Smith et al. 2015a). From a student / graduate identity perspective, a lack of positive affirmation impacts on future approaches to applications (Holmes 2013). Those self-reporting as working or middle class were just as likely to have applied for work experience. This is an encouraging indication of broad recognition of (and compliance with) the rules of the game that are cited as leading to positive graduate outcomes. Similarly, students were equally likely to apply for work experience, whether their parents had been to university or not. This is also encouraging, as, elsewhere, a lack of access to capitals (including understanding the rules of the game) has been observed in those from lower socio-economic groups or those first in their family to attend university (Abrahams 2016; Bathmaker 2015; Morrison 2014). Previous studies have noted that students need economic capital to take advantage of placements, particularly in other geographical locations (for example, Chillas et al. 2015). The location of the two universities in large urban settings (and financial centres), with local access to technology companies, may be contributory factors. The impact of a university's geographical location was highlighted by Shadbolt (2016) in terms of graduate mobility, with some locations retaining their graduates but those graduates suffering relatively high levels of unemployment. Analysis of published data revealed that graduates from low participation neighbourhoods were less likely to be working away from their location of study; BME graduates were generally more mobile, with $15 \%$ re-locating to London following graduation, joining the $28 \%$ of BME students who studied in London before finding employment (Shadbolt 2016). It is not clear from the data provided in Shadbolt's report whether this was a preference or necessity. Further, students from more privileged backgrounds are more able and likely to choose a university away from their family home and wealthier universities can support different approaches to employability than lower status institutions (Brookes 2017).

Finally, minority ethnic group students were slightly more likely to have applied for work experience (67\% compared with $61 \%$ of white students). This leads to a consideration of the next step towards a successful attempt to gain work experience: an offer.

\section{Gaining work experience}

In this study, the data indicates a bias according to the students' backgrounds (self-reported class; whether parents had attended university) in terms of success in gaining work experience. For example, those whose parents had attended HE were more likely to have been offered work experience. However, the survey did not capture information about the application process. It is likely that social capital is a factor in this finding. 
Bourdieu defines social capital as "the aggregate of the actual or potential resources which are linked to possessions of a durable network of more or less institutionalized relationships of mutual acquaintance or recognition" (1985, 248). As observed by Allen et al. (2013) for creative industry students, participants may have used contacts to explore or gain access to work experience, for example through their parents' social and professional networks. Hezlett and Gibson (2007) describe how social capital is mobilised in this context to create value from social ties. Bathmaker et al. (2013) observe that certain students can "more readily mobilise several forms of capital simultaneously, for example combining cultural capital in the form of 'what they know' with social capital in the form of "who they know"' (p726). The social networks of graduate parents are more likely to contain graduates/ professionals with access to non-competitive paid and unpaid work experience combined with the economic capital required to take advantage of these opportunities (Abrahams 2016).

This study also found a difference when it came to ethnicity, with BME students less likely to have been offered work experience following an application (60.3\% of White students were offered work experience, compared with $52 \%$ of BME students). Given the small sample size (84 students answered this question, reflecting the number who had applied for work experience), the comparison is not significant, but still worrying, as it reflects the graduate employment profile reported by Shadbolt (2016), where BME graduates had an unemployment rate of $17.3 \%$, compared with $11.2 \%$ among white graduates. Furthermore, if in work, BME graduates in Shadbolt's review (2016) were more likely to be in non-graduate level employment (31\% BME compared to $17 \%$ white).

This is not only an issue for computer science. Wilton's (2011) study of management graduates post-placement found that "on virtually all measures of labour market attainment, minority ethnic graduates reported inferior outcomes compared to their white peers" (p96). Measures included job satisfaction, career satisfaction, degreelevel employment and salaries. In a study of state schools, Wallace (2017) found black middle class pupils acquiring "dominant cultural capital” (p14) but still finding their advancement impeded. Previously, Morley (2007) had found that employers "frequently overlooked the context and equity implications of employability skills", finding employer notions of employability to be "underpinned by classed, gendered and racialised ideological subtexts" (p205). The published literature on outcomes for minority ethnic groups is extensive and beyond the scope of this paper. This study uncovered an appetite for work experience amongst BME students, but found them to be less able to access it. Further, more nuanced results would be expected from studies that supported analysis of ethnicity at a finer level of granularity, and the intersections of ethnicity, gender and socioeconomic backgrounds.

\section{What next for universities, employers and government?}

The pilot study paired two universities with similarities and differences and gathered responses from seventy students in each. Findings indicated that there is a danger that increased access to work experience could entrench existing disadvantage and exclusion , Before universities and employers act on the Shadbolt recommendation to increase work experience, the study should be repeated with a wider range of universities, including universities outside large cities and 'elite' universities, where attitudes may vary to those uncovered here (e.g. see Brooks, 2017). Certainly, further exploration of student attitudes to (and experiences of) work experience is essential if the Shadbolt recommendation for more access to work experience is to be realised and effective. Furthermore, higher education alone cannot solve this problem; HE is "necessary but not sufficient, one part of a chain of institutional effects" (Marginson, 2016, 431). While some work has been conducted (for 
example, Smith \& Smith 2016), a critical exploration of employer attitudes is also necessary to complete the picture.

\section{Conclusion and recommendations}

The driver for this research was a recognition by the UK government of a problem with unemployment amongst computing graduates, leading to the commission of the Shadbolt Review (2016). HE has been challenged to identify potential solutions to this problem and inform public policy, by initiating action in the university sector and with employers in the IT industry. There is already a well-established history of industrial placements and other work experience opportunities within the university sector, and this study provides further evidence that these opportunities are recognised and welcomed by students. As discussed, there are a number of competing factors that have resulted in a decline in the uptake of these opportunities in recent years, and the view expressed in the Shadbolt Report that reinvigorating work experience opportunities and activities would have a positive impact on graduate employment in computing is not challenged by this study. However, it is also clear from the study that the major issue is not student willingness to engage in work experience, but the availability of work experience opportunities, particularly for BME students.

In many ways, computing has been a success story in modern UK Higher Education, as it has consistently attracted the highest percentage of students from Low Participation Neighbourhoods (LPN) and BME students, suggesting that the subject is seen as an opportunity for advancement by many students. In reality, although computing graduates have a relatively high unemployment rate in graduate terms, for students coming from LPN and BME communities such unemployment rates are very low compared with their own communities, and the success rate of computing graduates in finding relevant graduate employment is of more relevance. This creates a confounding factor in considering this issue, since the perception of students from disadvantaged backgrounds may be quite distinct from government policy makers and university management. However, what is eminently clear from this research is that students coming from disadvantaged backgrounds do not possess the economic, cultural, social and symbolic capitals to compete equally in the graduate employment marketplace. Therefore, work experience opportunities should provide the mechanism by which the absence of these capitals can be mitigated and overcome (at least to some extent), assuming the students concerned are given equal access to such opportunities and employers continue to prioritise relevant work experience in their graduate recruitment decisions.

Within the two universities in the study, students were generally aware that work experience was beneficial as part of their degree study and they were prepared, where possible, to get involved in the necessary employability and application processes. They need to be welcomed by employers with recruitment approaches that value equality and diversity and view work experience as a chance for students to learn new technical and soft skills. However, with increased pressure on the placement 'market', there is a danger that employers will instead continue to raise their expectations that placement students will already be socially sophisticated, confident, and able to access the economic, social and cultural capitals that create winners and losers (Chillas et al. 2015) often inappropriately referred to as "work-ready". Employers may also mistakenly accord these characteristics with students' apparent ethnicity. To expand access to work experience, universities need to develop their understanding of students' diverse forms of cultural capital and any barriers associated with students' ethnicity, 
then work with employers to challenge the (often unconscious) bias inherent in recruitment, in order to open up work experience and placement opportunities. It is here that public policy has a role in promoting recruitment and employment procedures that are genuinely meritocratic, blind to ethnicity, gender, and socioeconomic background, and provide mechanisms to employment that encourage engagement rather than a hurdles race that eliminates anyone not fitting a predefined, and often flawed, profile. It is important to recognise that demonstrating an open, unbiased and meritocratic process for work experience opportunities is likely to increase the uptake of these opportunities by the very students the process is seeking to engage.

This study has drawn from existing research on economic, social, and cultural capital to demonstrate that the issues of unemployment amongst computing graduates have their roots in the success of the discipline in attracting students from lower participation and BME communities. A number of confounding issues arise: including student vs. establishment perceptions of employability; employer bias; employer expectations of work-ready interns and graduates; and the need to establish genuinely meritocratic recruitment and employment procedures. As indicated, there is a need to carry out further research, based on this model, at a range of universities, before moving forward on further work experience models. This research has opened up an area that was previously incompletely explored, and has developed some robust, empirical evidence to demonstrate that there is a problem to address. It has clearly demonstrated that, while the arguments for improving the work experience for students in HE proposed by Shadbolt are valid, the mechanisms need careful planning and consideration to ensure that there is equality of opportunity for all computing students, and that the industry develops a genuinely meritocratic model for recruitment and employment.

\section{Acknowledgments}

Thanks to Martina Aderonke Bella, Lyndsey Jenkins, Sean McKeown, Joseph Osunde, and Todd Richter for helping to gather the survey data.

\section{References}

Abrahams, J. (2016). Honourable mobility or shameless entitlement? Habitus and graduate employment. British Journal of Sociology of Education, 18(1), 1-13.

Allen, K., Quinn, J., Hollingworth, S., \& Rose, A. (2013). Becoming employable students and 'ideal'creative workers: exclusion and inequality in higher education work placements. British Journal of Sociology of Education, 34(3), 431-452.

Bathmaker, A. M., Ingram, N., \& Waller, R. (2013). Higher education, social class and the mobilisation of capitals: Recognising and playing the game. British Journal of Sociology of Education, 34(5-6), 723-743.

Bathmaker, A. (2015). Thinking with Bourdieu: thinking after Bourdieu. Using 'field' to consider in/equalities in the changing field of English higher education. Cambridge Journal of Education, doi:

0.1080/0305764X.2014.988683 
BIS (2016). Computer Science Graduate Employability: qualitative interviews with graduates. BIS Research paper 274. https://www.gov.uk/government/uploads/system/uploads/attachment_data/file/523079/bis-16-114computer-science-graduate-employability.pdf. Accessed 30 May 2017.

Blackwood, N. (2016). Digital skills crisis: second report of Session 2016-17. House of Commons Science and Technology Committee Report.

https://www.publications.parliament.uk/pa/cm201617/cmselect/cmsctech/270/270.pdf. Accessed 30 May 2017.

Borlagdan, J. (2015). Inequality and 21-year-olds' negotiation of uncertain transitions to employment: a Bourdieusian approach. Journal of Youth Studies, 18(7), 839-854.

Bourdieu, P. (1977). Outline of a Theory of Practice. Cambridge: Cambridge University Press.

Bourdieu, P. (1985). The genesis of the concepts of habitus and field. Sociocriticism, 2(2), 11-24.

Bourdieu, P. (1990). In Other Words: Essays Towards a Reflexive Sociology. Stanford: Stanford University Press.

Bourdieu, P. (2000). Pascalian Meditations. Cambridge: Polity Press.

Brooks, R. (2017). Understanding the higher education student in Europe: a comparative analysis, Compare: A Journal of Comparative and International Education, DOI: 10.1080/03057925.2017.1318047

Brown, P., Hesketh, A., \& Williams, S. (2004). The mismanagement of talent: employability and jobs in the knowledge based economy. Oxford: Oxford University Press.

Brosnan, C. (2017). Bourdieu and the future of knowledge in the university, in L. Adkins, C. Brosnan and S. Threadgold (Eds.) Bourdieusian Prospects (pp. 49-70). Abingdon: Routledge.

Burke, C. (2015). Habitus and Graduate Employment: A Re/Structured Structure and the Role of Biographical Research. In C. Costa and M. Murphy (Eds.) Bourdieu, Habitus and Social Research. The Art of Application (pp. 55-73). London: Palgrave Macmillan.

Carbone, A. \& Hamilton, M. (2016). Pizza with university ICT students: what do students' [sic] expect employers want from them? In Proceedings of the Australasian Computer Science Week Multiconference, Canberra, Australia, February 2016. NY: ACM. doi: 10.1145/2843043.2843345.

Chillas, S., Marks, A., \& Galloway, L. (2015). Learning to labour: an evaluation of internships and employability in the ICT sector. New Technology, Work and Employment, 30(1), 1-15.

Clark, M. \& Zukas, M. (2016) Understanding successful sandwich placements: A Bourdieusian approach, Studies in Higher Education, 41(7), 1281-1295.

Darr, A. \& Warhurst, C. (2008). Assumptions, Assertions and the Need for Evidence Debugging Debates about Knowledge Workers. Current Sociology, 56(1), 25-45. 
Docherty, D., Jones, O., \& Sileryte, I. (2015). Growing experience: a review of undergraduate placements in computer science for the Department of Business, Innovation and Skills. National Centre for Universities and Business.

http://www.ncub.co.uk/index.php?option=com_docman\&view=download\&category_slug=reports\&alias=183growing-experience \&Itemid=2728. Accessed 20 June 2017.

Donnelly, R., Grimshaw, D., \& Miozzo, M. (2011). Does the UK have a 'comparative institutional advantage' that is supportive of the IT services sector? New Technology, Work and Employment, 26(2), 98-112.

Farenga, S. \& Quinlan, K. (2015). Classifying university employability strategies: three case studies and implications for practice and research. Journal of Education and Work, doi: 10.1080/13639080.2015.1064517

Fincher, S. \& Finlay, J. (2016). Computing graduate employability: sharing practice. London: Council of Professors and Heads of Computing. https://cphcuk.files.wordpress.com/2016/01/computinggraduateemployabilitysharingpractice.pdf. Accessed 30 May 2017.

Greenbank, P. (2011). 'I'd rather talk to someone I know than somebody who knows'-the role of networks in undergraduate career decision-making. Research in Post-Compulsory Education, 16(1), 31-45.

HEFCE (2015). Differences in employment outcomes: Equality and diversity characteristics. HEFCE. http://www.hefce.ac.uk/pubs/year/2015/201523/. Accessed 21 April 2017.

HESAa. Destinations of full-time first degree leavers. Higher Education Statistics Agency. https://www.hesa.ac.uk/data-and-analysis/students/overviews?keyword=590\&breakdown[]=578\&year=2. Accessed 20 May 2017.

HESAb. Courses by subject area and sex. Higher Education Statistics Agency. https://www.hesa.ac.uk/data-andanalysis/students/courses Accessed 08 August 2017.

Hezlett, S. A., \& Gibson, S. K. (2007). Linking mentoring and social capital: Implications for career and organization development. Advances in Developing Human Resources, 9(3), 384-411.

Holmes, L. (2013). Competing perspectives on graduate employability: possession, position or process? Studies in Higher Education, 38(4), 538-554.

Hunt, V., Layton, D., \& Prince, S. (2015). Why Diversity Matters. McKinsey \& Company. http://www.mckinsey.com/business-functions/organization/our-insights/why-diversity-matters. Accessed 24 August 2017.

Jackson, D. (2014). Factors influencing job attainment in recent Bachelor graduates: evidence from Australia. Higher Education, 68(1), 135-153.

Marginson, S. (2016). The worldwide trend to high participation higher education: Dynamics of social stratification in inclusive systems. Higher Education, 72(4), 413-434. 
Morrison, A. R. (2014). 'You have to be well spoken': students' views on employability within the graduate labour market. Journal of Education and Work, 27(2), 179-198.

Morley, L. (2007). The X factor: employability, elitism and equity in graduate recruitment. Twenty-First Century Society, 2(2), 191-207.

Navarro, Z. (2006). In Search of a Cultural Interpretation of Power: The Contribution of Pierre Bourdieu. IDS Bulletin, 37(6), 11-22.

O'Shea, S. (2016). Avoiding the manufacture of 'sameness': first-in-family students, cultural capital and the higher education environment. Higher Education, doi:10.1007/s10734-015-9938-y

Ramirez, N., Smith, S., Smith, C., Berg, T., Strubel, B., Main, J., \& Ohland, M. (2016). From Interest to Decision: A Comparative Exploration of Student Attitudes and Pathways to Co-op Programs in the United States and the United Kingdom. International Journal of Engineering Education, 32(5A), 1867-1878.

SFC (n.d.). Guidance notes and code lists for completion of FES data 2016-17. Scottish Funding Council. Retrieved from http://www.sfc.ac.uk/communications/Guidance/2016/SFCGD032016.aspx

Shadbolt, N. (2016). Shadbolt Review of Computer Sciences Degree Accreditation and Graduate Employability. London: BIS. https://www.gov.uk/government/publications/computer-science-degree-accreditation-andgraduate-employability-shadbolt-review. Accessed 30 May 2017

Silva, P., Lopes, B., Costa, M., Seabra, D., Melo, A.I., Gonçalo, E., \& Paiva Dias, G. (2016). Stairway to employment? Internships in higher education. Higher Education, doi:10.1007/s10734-015-9903-9

Sin, C. \& Neave, G. (2016). Employability deconstructed: perceptions of Bologna stakeholders. Studies in Higher Education, 41(8), 1447-1462.

Smith, S. (2016). The conundrum of computer science. Times Higher Education https://www.timeshighereducation.com/features/what-should-we-be-teaching-the-next-generation-of-computerscientists. Accessed 30 May 2017.

Smith, S., Berg, T., \& Smith, C. (2015a). Making co-op work: An exploration of student attitudes to co-op programs. Proceedings of Frontiers in Education Conference (FIE), 2015 (pp.1-6). IEEE.

Smith, C., \& Smith, S. (2016). Matching and mismatch: Understanding employer expectations of work placement applicants. In ACEN 2016 Conference supporting work-integrated learning in Australia (p. 32).

Smith, S., Smith, C., \& Caddell, M. (2015b). Can pay, should pay? Exploring employer and student perceptions of paid and unpaid placements. Active Learning in Higher Education, 16(2), 149-164.

Smith, S., Smith, C., Taylor-Smith, E., \& Fotheringham, J. (2017). Exploring student identity through a university-wide graduate employability initiative. Asia-Pacific Journal for Cooperative Education.18(1), 15-24. 
Social Mobility Advisory Group (2016). Working in partnership: enabling social mobility in higher education the final report of the Social Mobility Advisory Group. Universities UK. http://www.universitiesuk.ac.uk/policyand-analysis/reports/Documents/2016/working-in-partnership-final.pdf. Accessed 21 April 2017.

Social Mobility Commission (2016). Socio-Economic Diversity in Life Sciences and Investment Banking. Social Mobility Commission.

https://www.gov.uk/government/uploads/system/uploads/attachment_data/file/549994/Socioeconomic_diversity_in_life_sciences_and_investment_banking.pdf. Accessed 21 April 2017.

Spiegler, T., \& Bednarek, A. (2013). First-generation students: what we ask, what we know and what it means: an international review of the state of research. International Studies in Sociology of Education, 23(4), 318-337.

Szolnoki, G. \& Hoffmann, D. (2013). Online, face-to-face and telephone surveys-Comparing different sampling methods in wine consumer research. Wine Economics and Policy, 2(2), 57-66.

Tomlinson, M. (2017). Forms of graduate capital and their relationship to graduate employability. Education+ Training, 59(4), 338-352.

Tymon, A. (2013). The student perspective on employability. Studies in Higher Education, 38(6), 841-856.

UKCES. (2015). Reviewing the requirement for high level STEM skills. UK Commission for Employment and Skills.

https://www.gov.uk/government/uploads/system/uploads/attachment_data/file/444052/stem_review_evidence_r eport_final.pdf Accessed 28 August 2017

Wallace, D. (2017). Cultural capital as whiteness? Examining logics of ethno-racial representation and resistance. British Journal of Sociology of Education, 1-17.

Waller, R. (2011) The Sociology of Education, in B. Dufour \& W. Curtis (eds.) Studying Education: Key disciplines in education studies Maidenhead: Open University Press

Wilton, N. (2011). Do employability skills really matter in the UK graduate labour market? The case of business and management graduates. Work, Employment and Society, 25(1), 85-100.

Yamak, S., Ergur, A., Özbilgin, M.F., \& Alakavuklar, O.N. (2016). Gender as Symbolic Capital and Violence: The Case of Corporate Elites in Turkey. Gender, Work \& Organization, 23(2), 25-146. 